\title{
TO COMPARE THE EFFICACY AND SAFETY OF THIOCOLCHICOSIDE AND CHLORZOXAZONE IN MUSCLE SPASM ASSOCIATED WITH LOW BACK PAIN
}

\author{
Dandolu Madhu Krishna Reddy', Praneeth Jagarlamudi²
}

1MS, Department of Orthopaedics, DBR and SK Super Speciality Hospital, Tirupati, Andhra Pradesh, India. 2MS, Department of Orthopaedics, DBR and SK Super Speciality Hospital, Tirupati, Andhra Pradesh, India.

\begin{abstract}
BACKGROUND
Higher incidence of LBP is reported in Indian population in younger patients due to occupational exposure and lack of exercise. In general, LBP is managed with the short-term use of Non-Steroidal Anti-Inflammatory Drugs (NSAIDs) and centrally acting skeletal muscle relaxants.

Aim- To compare the safety and efficacy of Thiocolchicoside and Chlorzoxazone in the treatment of low back pain associated with muscle spasm.
\end{abstract}

\section{MATERIALS AND METHODS}

This non-randomised controlled trial was conducted with 60 outpatients suffering from LBP who met inclusion and exclusion criteria. Finger-to-floor distance, Straight leg raising test, Pain assessment scale and Safety measures were used to measure the pain score on $1^{\text {st }}$ and $7^{\text {th }}$ day during treatment. The sample size estimation was also done at conveniences.

\section{RESULTS}

The baseline mean age for Group A and Group B was $48.9 \pm 8.52$ and $51.17 \pm 8.15$ respectively. On 1 st day, the mean pain score of Group A and Group B was $6.37 \pm 1.63$ and $6.43 \pm 1.79$ and on 7 th day the mean pain score was reduced to $2.17 \pm 1.31$ and $1.33 \pm$ 1.63 respectively. There was statistically significant reduction in mean pain score in Group B compared to Group A at the end of the treatment.

\section{CONCLUSION}

Both the drug regimens were found to be effective, while Chlorzoxazone had higher efficacy compared to Thiocolchicoside at the end of treatment, but it was not statistically significant.

\section{KEY WORDS}

Low Back Pain, Thiocolchicoside, Chlorzoxazone, Muscle Spasm.

HOW TO CITE THIS ARTICLE: Reddy DMK, Jagarlamudi P. To compare the efficacy and safety of thiocolchicoside and chlorzoxazone in muscle spasm associated with low back pain. J. Evolution Med. Dent. Sci. 2018;7(48):5150-5153, DOI: 10.14260/jemds/2018/1143

\section{BACKGROUND}

Low Back Pain (LBP), a very common complaint among middle-aged population affecting $90 \%$ of all adults at least once in a lifetime and is usually associated with "muscle spasm" that is responsible for persistence pain.[1] Higher incidence of LBP is reported in Indian population in younger patients due to occupational exposure and lack of exercise.

It is a major health and socio-economic problem ${ }^{[2]}$ and is associated with high costs of health care, work absenteeism and disablement.[3] In general, LBP is managed with the short-term use of Non-Steroidal Anti-Inflammatory Drugs (NSAIDs) and centrally acting skeletal muscle relaxants.[4] Unfortunately, NSAIDs have gastric intolerance, whereas most of the centrally acting muscle relaxants have central nervous system depressant side-effects such as sedation, dizziness,

'Financial or Other Competing Interest': None.

Submission 28-09-2018, Peer Review 10-11-2018,

Acceptance 17-11-2018, Published 26-11-2018.

Corresponding Author:

Dr. Dandolu Madhu Krishna Reddy,

Department of Orthopaedics,

DBR and SK Super SPER Speciality Hospital,

\#20-7-37, DBR Hospital Road, Near TMC,

Tirupati-517501, Andhra Pradesh, India.

E-mail: drmadhukrishnareddy@gmail.com

DOI: $10.14260 /$ jemds/2018/1143 impairment of coordination, mental confusion, weakness etc.[5] Chlorzoxazone, a centrally acting muscle relaxant act primarily at the level of the spinal cord and subcortical areas of the brain, where it inhibits multisynaptic reflex arcs involved in producing and maintaining skeletal muscle spasm. The exact mode of action is not clear, may be related to the sedative properties of the drug. The side effect profile is similar to that of most of other muscle relaxants, except for a limited number of reported cases of significant hepatotoxicity, particularly by chlorzoxazone.[6]

Thiocolchicoside is a semi-synthetic derivative of colchicine, a natural glycoside originated from flower seeds of superb gloriosa.[7] It has an affinity for the inhibitory glycine and gamma-aminobutyric acid (GABA)-A receptors i.e. have glycomimetic and GABA-mimetic activity, therefore shows muscle relaxant action. As it has GABA-mediated action, so it shows both myorelaxant as well as analgesic activity. It has demonstrated its clinical efficacy and safety in many clinical trials. $[8,9,10,11,12]$ It has also been reported that thiocolchicoside produces muscle relaxation without any subjective or objective sedative side-effects. ${ }^{[8]}$

Hence, the present study was undertaken to compare the efficacy and safety of thiocolchicoside and chlorzoxazone along with NSAIDS in patients with muscle spasm associated with acute lower back pain. 


\section{MATERIALS AND METHODS Study Design}

This non-randomised controlled trial was undertaken in the outpatient department of orthopaedics in DBR and SK Super Speciality Hospital, Tirupati. Patients attending the outpatient department were screened and assessed according to the specified inclusion and exclusion criteria. A total of 60 eligible patients were taken for the study. Study by convenient allocation technique since the duration of the study was few months. The patients were selected by convenience allocation technique. The sample size estimation was also done at conveniences.

\section{Inclusion Criteria}

Patients of either sex in the age range of 18 - 55 years with a history of LBP and muscle spasm were included in the study.

\section{Exclusion Criteria}

Patients having low back pain with muscle spasm due to malignancy, infection, osteoarthritis and associated with other chronic diseases were excluded. Patients having active peptic ulcer disease, patients allergic to NSAIDs and patients who were on NSAIDs and muscle relaxants within 7 days were excluded from the study.

\section{Criteria for Evaluation/ Finger-to-Floor Distance}

It was measured by flexion at the hip joint in a standing position. The patients were told to bend down as far as possible without bending the knees and try to touch the floor with their fingers. The remaining distance between the floor and fingertips was measured by the ruler in centimetres.[13]

\section{Straight Leg Raising Test}

In this test articular excursion of the hip in degrees on performing Lasegue's manoeuvre before inducing pain in the supine position, which involved gradually raising of lower extremity by flexing the hip with the knee in extension passively. The angle between the raised limb and table-top was measured.[13]

\section{Pain Assessment Scale}

Assessment of intensity of pain at rest and pain on movement was carried out on day 1 (Visit 1) and days 7 (Visit 2) by means of a $10 \mathrm{~cm}$ Visual Analogue Scale (VAS) ${ }^{[26]}$ as reported by a patient between 0 (No pain) and 10 (Unbearable pain). The patients were asked to score by ticking off the scale between 0 (No pain) and 10 (Unbearable pain).

\section{Safety Measures}

Side-effects such as tiredness, drowsiness, dizziness and alertness were noted based on history and observations of adverse reactions. Furthermore, global assessment of tolerability to therapy was assessed on a four-point scale of excellent/good/ average/ poor.

\section{Statistical Analysis}

At the end of the study, the collected data was compiled and analysed using SPSS version 25.0.

The difference between the thiocolchicoside and chlorzoxazone group before and after administration of the respective drugs were compared using unpaired t-test. Demographic data and percentage was calculated using chisquare test. $P$ value of 0.001 was considered significant.

\section{RESULTS}

\begin{tabular}{|c|c|c|}
\hline & Group A & Group B \\
\hline Age (Mean \pm SD) & $48.9 \pm 8.52$ & $51.17 \pm 8.15$ \\
\hline Males, n (\%) & $18(60.0)$ & $16(53.3)$ \\
\hline Females, n (\%) & $12(40.0)$ & $14(46.7)$ \\
\hline \multicolumn{2}{|c|}{ Table 1. Socio-Demographic Variables } \\
\hline
\end{tabular}

\begin{tabular}{|c|c|c|c|}
\hline & Group A & Group B & P value \\
\hline Day 1 & $24.3 \pm 11.41$ & $16.6 \pm 13.454$ & $<0.001$ \\
\hline Day 7 & $6.83 \pm 3.63$ & $2.67 \pm 2.155$ & $<0.001$ \\
\hline \multicolumn{4}{|c|}{ Table 2. Finger-to-Floor Distance } \\
\hline
\end{tabular}

The mean finger-to-floor distance of Group A patients on day 1 was $24.3( \pm 11.41) \mathrm{cm}$ and on day 7 was $6.83( \pm 3.63)$ $\mathrm{cm}$. This difference was statistically significant between day 1 and day 7. The mean finger-to-floor distance of Group B patients on day 1 was $16.6( \pm 3.454) \mathrm{cm}$ and day 7 was 2.67 $( \pm 2.155) \mathrm{cm}$. This difference was also statistically significant between the day 1 and day 7. Though the statistical data was significant improvement in the same group from day $1-7$, the comparison of betterment group was not significant $(\mathrm{P}$ value $<0.136)$.

\begin{tabular}{|c|c|c|c|c|}
\hline \multirow{2}{*}{$\begin{array}{c}\text { Lasegue's } \\
\text { Sign }\end{array}$} & \multicolumn{2}{|c|}{ Day 1 } & \multicolumn{2}{c|}{ Day 7 } \\
\cline { 2 - 5 } & Group A & Group B & Group A & Group B \\
\hline Normal & $23(76.7 \%)$ & $22(60 \%)$ & $27(90 \%)$ & $27(90 \%)$ \\
\hline Sedation & $2(6.7 \%)$ & $1(3.3 \%)$ & 0 & 0 \\
\hline Drowsiness & 0 & 0 & 0 & 0 \\
\hline GI disturbance & $5(16.7 \%)$ & $7(23.3 \%)$ & $3(10 \%)$ & $3(10 \%)$ \\
\hline Total & $\mathbf{3 0}(\mathbf{1 0 0} \%)$ & $\begin{array}{c}\mathbf{3 0} \\
(\mathbf{1 0 0} \%)\end{array}$ & $\mathbf{3 0}(\mathbf{1 0 0 \% )}$ & $\begin{array}{c}\mathbf{3 0} \\
\mathbf{( 1 0 0 \% )}\end{array}$ \\
\hline
\end{tabular}

Table 3. Lasegue's Sign of the Study Group at Day 1 and 7

On day 1, about $6.7 \%$ and $3.3 \%$ of the patients of Group A and Group B patients had sedation. 10\% of Group A and Group B patient had GI disturbance. There was a statistically significant difference between the Lasegue's sign of the Group A and Group B on day 1. At the end of day 7, about $90 \%$ of the Group A and Group B patients were normal by Lasegue's sign. This difference in Lasegue's sign was not statistically significant between the two groups (P value $<0.012$ ).

\begin{tabular}{|c|c|c|}
\hline & Group A & Group B \\
\hline Day 1 & $6.37 \pm 1.63$ & $6.43 \pm 1.79$ \\
\hline Day 7 & $2.17 \pm 1.31$ & $1.33 \pm 1.63$ \\
\hline \multicolumn{3}{|c|}{ Table 4. Visual Analogue Score } \\
\hline
\end{tabular}

The mean VAS scores of Group A patients was 6.37 ( \pm 1.63), which was reduced to 2.17 ( \pm 1.31 ), which was statistically significant between day 1 to day 7 . The mean VAS score of Group B patients on day 1 was 6.43 ( \pm 1.79 ), which was reduced to $1.33( \pm 1.63)$ on day 7 . This difference was statistically significant. The VAS scores were statistically significant between the two groups on day 7. On comparing the groups, there was not significant difference ( $P$ value0.010). 


\begin{tabular}{|c|c|c|}
\hline Lasegue's Sign - Day 7 & Group A & Group B \\
\hline Poor & $1(3.3 \%)$ & $2(6.6 \%)$ \\
\hline Average & $1(3.3 \%)$ & $1(3.3 \%)$ \\
\hline Good & $18(60 \%)$ & $13(43.3 \%)$ \\
\hline Excellent & $10(33.3 \%)$ & $14(46.7 \%)$ \\
\hline Total & 30 & 30 \\
\hline Table 5. Distribution of the Study Group according to \\
Global Scale \\
\hline
\end{tabular}

The global assessment scale has indicated that about $33.3 \%$ of the patients in Group A had the good grade $60 \%$ and $33.3 \%$ excellent grade among Group A patients. Among the Group B patients, $43.3 \%$ of the patients were graded as good and $46.7 \%$ were graded as excellent. This difference in grading of Global scale was statistically significant between Group A and Group B.

\section{DISCUSSION}

This study was conducted to compare the efficacy of Thiocolchicoside and chlorzoxazone. The main goal of the pharmacological intervention in low back pain is not only relief from the pain, but also to reduction of the muscle spasm and inflammation. Chlorzoxazone is a muscle relaxant which in addition to inhibition of mono- and multi-synaptic reflexes also regulates the blood supply to the skeletal muscles.[14] Thiocolchicoside being a spinal GABA agonist compound has been reported to exert inhibitory effect and result in muscle relaxation.[15] Unlike other muscle relaxants, both of these drugs have been reported to have less gastrointestinal side effects and sedative effects.[16]

Present study confirms the efficacy of both FDCs in the treatment of painful muscle spasm. The study reported a statistically significant improvement in the finger-to-floor distance on the $1^{\text {st }}(\mathrm{P}<0.001)$ and 7 th day $(\mathrm{P}<0.001)$ as compared to baseline on both the groups. However, the decrease in hand-to-floor distance was more pronounced within Group A as compared to Group B, though the difference between the two groups was not found to be statistically significant. A study by Cabitza et al had shown to improve the FFD more in Eperisone group similar to the results of this study after 7 days of treatment.[13] Maaz et al[17] have also supported the results of Cabitza et al. In contrary to these results, Rao et al[18] and Soonawala et al reported Thiocolchicoside is a better drug of choice in comparison with Eperisone.[12]

The mean VAS scores of Group A patients was $6.37( \pm$ 1.63), which was reduced to $2.17( \pm 1.31)$ which was statistically significant between day 1 and day 7 . The mean VAS score of Group B patients on day 1 was $6.43( \pm 1.79)$, which was reduced to $1.33( \pm 1.63)$ on day 7. There was a statistically significant difference between the two groups. Maaz et al[17] have also reported that the VAS score of pain decreased significantly in patients receiving Thiocolchicoside and Chlorzoxazone. Study by Soonawala et al[12] has also reported that both Eperisone and Thiocolchicoside decrease the muscle spasm.

The global assessment scale has indicated that about $33.3 \%$ of the patients in Group A had the good grade $60 \%$ and $33.3 \%$ excellent grade among Group A patients. Among the Group B patients, $43.3 \%$ of the patients were graded as good and $46.7 \%$ were graded as excellent. This difference in grading of Global scale was statistically significant between the two groups. No studies have reported the findings of
Global assessment and hence these study results were not compared with other studies.

The usual gastrointestinal side effects due to Thiocolchicoside and Chlorzoxazone have been reported and treated appropriately by using proton pump inhibitors.

\section{CONCLUSION}

Thiocolchicoside and chlorzoxazone are found to be effective drugs in relieving the lower back pain associated with muscle spasm. Chlorzoxazone was found to be more effective in terms of finger-to-floor distance and improvement in Lasegue's sign when compared to thiocolchicoside, which was not statistically significant.

In conclusion, Thiocolchicoside and chlorzoxazone along with NSAIDS for 7 days in the treatment of LBP significantly reduces the intensity of pain and improves the mobility without causing side-effects.

\section{REFERENCES}

[1] Gautschi OP, Hildebrandt G, Cadosch D. Acute low back pain - Assessment and management. Praxis (Bern 1994) 2008;97:58-68.

[2] Andersson GB. The epidemiology of spinal disorders. In: Frymoyer JW, editor. The Adult Spine: Principles and Practice. 2nd ed. New York: Raven Press; 1997. pp. 93-143.

[3] vanTulder MW, Koes BW, Bouter LM. A cost-of-illness study of back pain in The Netherlands. Pain. 1995;62:233-40.

[4] Chou R, Huffman LH. American Pain Society, American College of Physicians. Medications for acute and chronic low back pain: A review of the evidence for an American Pain Society/American College of Physicians clinical practice guideline. Ann Intern Med. 2007;147:505-14.

[5] Ketenci A, Ozcan E, Karamursel S. Assessment of efficacy and psychomotor performances of thiocolchicoside and tizanidine in patients with acute low back pain. Int J ClinPract. 2005;59:764-70.

[6] Powers BJ, Cattau EL, Jr Zimmerman HJ, Chlorzoxazone hepatotoxic reactions. An analysis of 21 identified or presumed cases. Arch Intern Med. 1986;146:1183-6.

[7] Umarkar AR, Bavaskar SR, Yewale PN. Thiocolchicoside as muscle relaxant a review. Int J Pharm Bio1 sci.2011;1:364-71.

[8] Patat A, Kleion MJ, Surjus A, Renault M, Rezvani Y, Granier J. Effects of acute and repeated doses of two muscle relaxants chlormezanone and thiocoside, on vigilance and psychomotor performance of healthy volunteers. Hum psychopharmacol.1991;6:28

[9] Tuzun F, Unalan H, Oner N, Ozguzel H, Kirazli Y, Lcagasioglu A, et al. Multicenter, randomized, doubleblinded, placebo-controlled trial of thiocolchicoside in acute low back pain. Joint Bone Spine. 2003;70:35661.

[10] Marcel C, Rezvani Y, Revel M. Evaluation of thiocolchicoside as monotherapy in low back pain. Results of a randomized study versus placebo. Presse Med.1990;19:1133-6. 
[11] Lahoti G. To evaluate efficacy and safety of fixed dise combination of Aceclofenac+ paracetamol + thiocolchicoside (acenac-MR) in the treatment of acute low back pain. J Indian Med Assoc.2012;110:56-8.

[12] Soonawalla DF, Joshi N. Efficacy of thiocolchicoside in Indian patients suffering from low back pain associated with muscle spasm. J Indian Med Assoc. 2008;106:331-5.

[13] Cabitza P, Randelli P. Efficacy and safety of experisone in patients with low back pain: A double blind randomized study. Eur Rev Med Pharmacol Sci.2008;12:229-35.

[14] Desai AA, Sachdeva PD, Arora BD. A comparative study of combined use of aceclofenac along with thiocochicoside and aceclofenac alone in patients diagnosed of low back pain. Int J Pharm Sci.2011;2:141-50.

[15] Magnusson SP, Simonsen EB, Aagaard P, Boesen J, Johannsen F, Kjaer M. Determinants of musculoskel et al flexibility: viscoelasticproperties, cross sectionalarea, EMG and stretchtolerance. Scand J Med Sci Sports. 1997 Aug; 7(4): 195-202.
[16] Chou R. Pharmacological management of low back pain.Drugs. 2010 Mar 5;70(4):387-402. doi: 10.2165/11318690-000000000-00000.

[17] Maaz SH, Khandelwal PN, Baig SM, Doifode SM, Ghotkar UM. Evaluation of efficacy and tolerability of eperisone and thiocolchicoside in treatment of low back pain associated with muscle spasm: An open label, prospective, randomized controlled trial. Int J Basic ClinPharmacol 2016;5:2669-74.

[18] Rao R, Panghate A, Chandanwale A, Sardar I, Ghosh M, Roy M, Banerjee B, Goswami A, Kotwal PP. Clinical comparative study: efficacy and tolerability of tolperisone and thiocolchicoside in acute low back pain and spinalmuscle spasticity. Asian Spine J. 2012 Jun;6(2):115-22. doi: 10.4184/asj.2012.6.2.115. Epub 2012 May 31. 